XXI.-Results of Removal and Transplantation of Ovaries. By F. H. A. Marshall, D.Sc., Carnegie Fellow and Lecturer on the Physiology of Reproduction, and W. A. Jolly, M.B., Assistant to the Professor of Physiology, University of Edinburgh. (From the Physiological Laboratory, University of Edinburgh.) (With Two Plates.)

(Real December 3, 1906. MS. received December 6, 1906. Issued separately May 8, 1907.)

It is well known that double ovariotomy, when performed prior to puberty, exercises a prejudicial effect not only upon the generative organs but also upon the whole organism. There is, however, some disagreement as to the results of this operation when performed after puberty, and particularly in regard to the occurrence of heat or menstruation.

It is the purpose of this paper to adduce further evidence upon this question, as well as to describe experiments the result of which indicates that the nature of the ovarian influence is chemical rather than nervous.

Numerous instances have been cited of the occurrence of menstruation after double ovariotomy. Thus three cases have been recently described by DoRAN (1905) in each of which the ovaries were believed to have been removed, and the greater part of the uterus was also removed, but where menstruation occurred at irregular intervals after the operation.* DorAN, however, records a large series of other cases in which menstruation ceased after ovariotomy. In a further case described by Pozzi, the recurrence of the catamenia after removal of the ovary is thought to have been due to the presence of a uterine fibroma; but Pozzr makes no suggestion as to why such a fibroma should have the effect supposed. A case of greater interest has lately been recorded by PINARD, in which ovariotomy was performed for mollities during pregnancy. After delivery the catamenia returned, and also the bad symptoms. Hysterectomy was then performed, and on inspection ovarian tissue was detected in the position from which the ovaries had been removed. It would seem probable that the other cases of menstruation taking place after double ovariotomy are to be similarly explained, on the assumption that the removal was not quite complete and that the ovarian tissue which remained underwent hypertrophy. That this interpretation is correct is rendered the more probable in view of the cases referred to by Doran (1902), in which pregnancy occurred after the supposed removal of both ovaries. Since the publication of Doras's paper in which the literature is given, a further case of pregnancy after double ovariotomy has been put on record by MeREDT'H (1904).

It is a not uncommon practice among veterinarians to remove the ovaries of dogs

* BeLl (1906), referring to such cases in a recent paper, is disposed to ascribe the continuance of menstruation to the presence of the uterus, which he regards as sufficient for the purpose even in the complete absence of the ovary.

TRANS. ROY. SOC. EDIN., VOL. XIV. PART III. (NO. 21). 
in order to prevent them from breeding. We understand from Principal M'CALL, of Glasgow, that normal heat does not occur in dogs on whom this operation has been performed.

Ovariotomy is also sometimes performed on mares, and usually with the object of repressing those vicious symptoms which so often occur during the œstrous periods and render the animals at such times almost or quite unworkable. Details of fifty consecutive cases of ovariotomy in troublesome mares are given in two papers by HobDay $(1902,1906)$, who shows that the operation is frequently followed by perfectly successful results. From these papers it does not appear certain that cestrus is completely prevented after the removal of the ovaries, but the violent symptoms which rendered the mares useless for work were in nearly every instance suppressed. In one case ovariotomy was undertaken to prevent ostrus, and the result was regarded as having been "satisfactory." Other mares are described as having been operated on because they were "always in œestrum," and so, presumably, unworkable, and in these cases also the result of the ovariotomy is said to have bcen satisfactory.

The statements of certain writers regarding the condition of the uterus subsequent to double ovariotomy are in opposition to the views of those who hold that heat and menstruation may occur after the performance of that operation. Thus Knauer (1900) says that removal of the ovaries in rabbits brings about a premature menopause, the uterus undergoing atrophy. Similar statements have been made by Sokoloff (1896), Hofnwier, Benkiser (1891), and Buys and Vandervelte (1894). Hofmeikr and Benkiskr, however, ascribe the degenerative changes in the generative organs after ovariotomy to an insufficiency in the blood supply consequent upon the operation of removal, while BuYs and $V_{\text {ANDERVELTE }}$ are disposed to regard these changes as being the indirect result of an assumed severance of nerves passing to the uterus and vagina. Limon (1904), on the other hand, states that he found no sign of atrophy in the generative organs after the transplantation of the ovaries to an abnormal position, and, therefore, that the respective explanations offered by Hofmeifr and Benkiser and by Buys and Vandervelte are inadequate. But LiMON does not appear to have made more than a superficial examination of the organs to which he refers; he mentions also that the experiments of Knauer, Ribbert, and Rubinstein point to the same conclusion as his own, and support the view that the proper nutrition of the uterus is dependent upon the existence of an internal ovarian secretion.

Our own observations on this matter are such as seem to us definitely to exclude the possibility of the recurrence of normal heat after the ovaries have been removed for a period longer than a few months.

The blood supply of the uterus is derived largely from the uterine artery which is given off in the pelvis, and is in no way interfered with by the operation of ovariotomy. The ovarian artery in the experiments described below was necessarily severed at a point a little short of its entrance to the ovaries, and in all our experiments the blood supply of the uterus may be said to have been unimpaired. 


\section{Effects of Castration.}

With the object of observing what changes, if any, are brought about in the uterus by the removal of the ovaries, we have performed ovariotomy in thirty-three rats. Both ovaries were removed by an anterior median incision. The rats were killed at periods varying from two and a half to eight months after operation, and the uterus examined histologically. In the great majority of cases the uterus has been found to exhibit divergence from the normal in a greater or less degree. It is small and atrophied. The mucosa is thin and poor in cells, the mucosal glands are small, while the connective tissue is increased in amount. In some cases, as in fig. 6, which represents a uterus examined six months after castration, the histological changes are very marked: the muscular wall is thinned and its connective tissue increased; the mucous membrane is in a condition of great fibrous overgrowth, and the glands are hardly recognisable.

All stages of degeneration can be seen from the condition found about two months after operation, where the uterus is small and shows commencing atrophy, to the extreme degree described above.

In several cases the uterus was found to have become distended with clear fluid, and on microscopical examination the uterine wall was seen to be thinned, the mucosa being represented only by a few cells and some fibrous tissue, and the lining epithelium converted into a stratified squamous epithelium.

In more than one instance an appearance resembling endometritis was observed after castration, the mucosa being swollen and the epithelium desquamated. There was in these cases no inflammation at the site of operation nor obvious source of septic infection, and the condition may probably be interpreted as a degenerative one.

In one case, where no atrophic appearances were presented by the uterus, a small portion of one ovary, in which at least two corpora lutea had become developed, was found, on post-mortem examination, to have been left behind at the operation.

The effect produced upon the uterus by removing the ovaries, and transplanting them to abnormal positions, will be discussed after we have described our experiments on ovarian transplantation.

\section{Ovarian Transplantation.}

The grafting of various organs of the body (such as the thyroid, suprarenal, kidney, ete.) in abnormal positions in the same individual, or in normal or abnormal positions in other individuals, has been attempted by numerous investigators with a varying amount of success. As a general rule, heteroplastic transplantation (i.e. from one individual to another) has been found far more difficult to carry out than homoplastic transplantation (i.e. in the same individual) ; wbile the latter, in the case of many organs, has not so far been successfully accomplished.

Transplantation of the testis has been attempted by RIBBERT (1898), but without success, the grafted organ undergoing a rapid degeneration. ShatTock and Seligmann 
(1904), however, state that in attempting to remove the testes of fowls the organs in some cases broke up, minute fragments being left behind, and, becoming attached to the adjacent viscera or abdominal wall, continued to produce spermatozoa and act as functional glands. In these cases it would appear that transplantation was unintentionally affected.

Ovarian transplantation has been practised or attempted by various gynæcologists, surgeons and others. The grafts in some instances are described as having been successful; but histological descriptions of the transplanted ovaries are often omitted, and these when they are given are very rarely illustrated by figures. The only attempt, so far as we are aware, adequately to illustrate microscopic sections of transplanted ovaries, appears to be that of Limon (1904), whose experiments in grafting do not seem to have been so successful as our own.

The cases described by Moras (1896), Duduey (1897), and Glass (1899), in which ovaries were grafted into women whose own ovaries had been previously removed, have been mentioned in our previous paper (1905). It should be noted, however, that no record has been made (at least, so far as we are aware) of the further history of these cases since they were first published, and, although they have been described as successful, in the absence of post-mortem examination there is no direct evidence that this was the case.

The case recently described by MorRIs (1906) in which a woman with a grafted ovary (her own ovaries having been extirpated) is said to have become preguant and given birth to a child about four years after the operation, is still more problematical. A possible explanation of this case is that a portion of one of the woman's own ovaries had been accidentally left behind at the time of the operation of removal and had subsequently undergone hypertrophy and given rise to the ovum, which afterwards became fertilised, just as in the cases described by Doran referred to above. If this be the true explanation, there is no need to assume that the transplanted ovary had become functional. Morris states that the woman did not menstruate until four months after the transplantation had been effected, and then menstruated at irregular periods. There is no post-mortem evidence that in any of these cases the graft had been successfully attached.

Cramer, of Bonn (1906), has recently recorded a case in which the ovary of a woman suffering from osteomalacia was removed and transplanted into a second woman whose genital organs were much atrophied. The operations were performed simultaneously. As a result of the transplantation the genital organs of the woman in whom the ovary was grafted are said to have become normal, menstruation started once more, and the breasts secreted colostrum. The author regards this case as affording further evidence that transplanted ovaries can maintain their functions.

The earliest attempts to transplant ovaries in animals seem to have been those of Romanes, who refers to them in Darwin and After Darwin, vol. ii. (1895). These experiments were unsuccessful. 
KNAUER (1896) removed an ovary from a rabbit and transplanted it upon the uterine horn of the same side in the same individual. After several months he killed the rabbit, when he found the grafted ovary, which contained Graafian follicles, some degenerate but some apparently healthy.

GriconIEFF (1897) performed a series of experiments in which he transplanted ovaries of adult rabbits to the broad ligament or the peritoneum of the vesico-uterine pouch. Subsequently he found that the grafts had become successfully attached and contained follicles in a state of complete preservation. In four cases pregnancy is stated to have occurred, the ova being supposed to have been derived from the grafted ovaries.

GrigoriefF also mentions two cases in which ovaries were transplanted from one individual to another (heteroplastic grafting). Both of these are said to have been successful, but no description is given of the transplanted ovaries.

Arendt (1898), who attempted to transplant the ovaries of eleven rabbits to the broad ligament, was unsuccessful in all cases. This author criticises the results obtained by Knauer and Grigoriefr, and concludes that in the cases of pregnancy described by the latter the ova were produced in fragments of untransplanted ovarian tissue which had been left in the normal position. ArEndT expresses doubts as to the possibility of successfully transplanting ovaries.

RIBBER'T (1898), working on the guinea-pig, obtained results in homoplastic transplantation which, in a general way, are confirmatory of those of KNauer and Grigoriefr. During the first month after transplantation the peripheral part of the grafted ovaries remained unaltered but the central part became transformed into connective tissue. At later periods, however, the central portion of the ovaries was again found to contain follicles. RibBert attributes this fact to the conditions of better nutrition which the ovaries had probably attained after a month of transplantation.

Rubinstein (1898) was also successful in transplanting rabbits' ovaries to abnormal positions in the same individuals.

KNAUER, in a later paper (1899), has described certain further experiments in transplanting ovaries. These were to a great extent successful. Knauer, however, states that a portion of the grafted ovary invariably died, but the remaining part in a large percentage of cases contained healthy follicles. Thirteen further cases are mentioned in which an attempt was made to transplant ovaries from one individual into another (heteroplastic transplantation), but each of these is reported as having been unsuccessful.

M'Cone (1899), in a preliminary report, briefly describes two cases of heteroplastic grafting. In one of these the ovaries of a rabbit were implanted in another rabbit (previously castrated), and the latter is stated to have subsequently given birth to five young. In a second experiment the ovaries of a bitch are described as having been successfully grafted upon a rabbit. Other experiments are mentioned in which homoplastic transplantation (i.e. transplantation in the same individual) of rabbits' 
ovaries is said to have been effected. The accounts are very meagre, and do not appear to have been followed by a full report; this is the more to be regretted since other experiments of a similar nature are mentioned as having been in progress. In the absence of a full report stating the results of the entire series of experiments and entering into histological detail, we hesitate to express ourselves regarding the value of M'Cone's work.

Herlitzka (1900) has described forty experiments in which he tried to graft the ovaries of guinea-pigs upon the bodies of other individuals, some female and some male. The experiments were unsuccessful in all cases except one, the ovaries undergoing a process of degeneration with greater or less rapidity. The single exception was the case of an ovary which, after transplantation for forty-two days, was found to contain follicles with an apparently normal ovum. The ovary contained other follicles which were degenerate. In this experiment the ovary had been transplanted to the body of a female. Herlitzka describes those cases in which the ovaries are transplanted to new positions in the same individuals as homoplastic transplantations, while the cases in which they are implanted on other individuals he denotes as heteroplastic transplantations. We have adopted this terminology in the present paper.

SchulTz (1900) has given an account of five experiments in which the ovaries of guinea-pigs were grafted upon the bodies of males. All the five experiments are said to have been successful. ScHultz's results have been criticised somewhat severely in a further paper by HerLitzka (1900), who complains of insufficiency of detail in the descriptions of the experiments.

Fò (1900) has described a series of experiments in which the ovaries of newly born or very young rabbits were grafted in the normal position in older rabbits of various ages whose own ovaries had been removed. Some of the grafts are said to have taken successfully and even to have undergone growth after transplantation. In five other experiments the young ovaries were grafted without first removing the ovaries of the animals upon which the grafts were made, and of these three are said to have "yielded a positive result"; but no description of the grafts is given. In other cases in which embryo ovaries were grafted in old rabbits which had reached the menopause, the grafts degenerated very rapidly and were absorbed without leaving any trace.

Amico-Roxas (1901) has briefly described heteroplastic and homoplastic transplantation of sheep's ovaries, but without giving any account of the histological structure of the transplanted ovaries.

MorRIs (1903), whose cases of ovarian transplantation in the human female have already been referred to, has also mentioned that he carried out some experiments on heteroplastic transplantation in rabbits. He states that the grafted ovaries continued to furnish ova and to elaborate an internal secretion for some months, but that they then underwent degeneration. He does not, however, give any account of his experiments, and omits to state the evidence upon which he bases his conclusions that the transplanted ovaries continued to provide an internal secretion. 
Limon (1904) performed four homoplastic transplantations of rabbits' ovaries, which were grafted on the peritoneum or between the muscles of the abdominal wall. The follicles all showed a tendency to degenerate; but the interstitial cells, on the other hand, after a short period of starvation subsequently recuperated, and acquired a condition of perfect vitality. There is, however, no mention of the Graafian follicles having done likewise, or of corpora lutea having been formed. Figures are given illustrating the recuperation of the interstitial tissue.

BAsso (1905) has performed homoplastic grafts, and also heteroplastic, in rabbits and guinea-pigs. The ovaries were usually grafted on to the mesometrium. Some success was attained, especially in the homoplastic implantations. No figures, however, are given. In the heteroplastic implantations the stroma is described as laving become necrotic Ovaries were also transplanted to males, and, since these were not less successful, the author concludes that presence of the testis did not exert any special inhibitory influence.

Bond (1906), in a recent paper on "Some Points on Uterine and Ovarian Physiology and Pathology in Rabbits," has referred to a few experiments in which he transplanted ovaries to abnormal positions in the same individuals (homoplastic grafts). Only one experiment appears to have been at all successful. In this case "a somewhat modified and degenerate corpus luteum of pregnancy" was found, after the ovary had been grafted for about a month, in a pregnant animal whose other ovary had been allowed to remain in situ.

Our transplantation experiments have been performed on rats.

\section{Homoplastic Implantation.}

The ovaries of twenty rats were excised and transplanted to another situation within the peritoneal cavity, being attached by means of a catgut stitch to the parietal peritoneum. Of these cases, the following eight may be described as entirely successful :

1. The grafted ovaries (fig. 1) were allowed to remain for two and a quarter months. When examined, they were found to contain follicles and ova. The follicular epithelium was normal, and groups of interstitial cells were visible in the stroma. The germinal epithelium had disappeared from the outside of the ovary. Several large cysts, lined with squamous epithelium, were also present. The ovaries were examined in the month of January, i.e. before the breeding season of the rat.

2. The graft was here left for two months, and the rat was killed in the beginning of the breeding season. The graft contains follicles, and a large number of corpora lutea of apparently different ages.

3. This graft (fig. 2) was left for two months, and showed, on microscopic examination, follicles, ova, and corpora lutea. The rat was killed during the breeding season.

4. The graft was left for two and a half months, and exhibited follicles, corpora lutea, and a cyst. Killed during breeding season. 
5. Graft left for three months. Normal corpora lutea and cysts were found present. Killed during breeding season.

6. Graft left for eight months. A few corpora lutea and follicles were present, with relatively large amount of stroma. This rat was killed in October, i.e. during the nonbreeding season.

7. Graft left for five months. The ovarian stroma was unaltered. Some luteal tissue, follicles, and cysts were also present.

8. Graft left for six months. Shows follicles and corpora lutea.

In seven other cases of homoplastic implantation partial success was obtained. The tissue is recognisably ovarian, but has become considerably altered.

Five experiments must be described as unsuccessful, the grafted tissue either being entirely absorbed or replaced by connective tissue. Cysts were found present in each of these cases.

\section{Heteroplastic Implantation.}

Six operations were performed in which ovaries were removed from one rat and implanted on the peritoneum of another.

Two cases were attended with success.

1. The ovaries were removed from a rat and transplanted to the peritoneum of another whose own ovaries had previously been removed. The graft (fig. 3) was left for three and a quarter months, when the animal was killed. Examined microscopically, the graft showed ovarian stroma and corpora lutea. The two rats were possibly of the same litter, but this was not certainly known.

2. The ovaries were removed from a rat and transplanted to the peritoneum of another whose own ovaries were not removed. The two rats were of the same litter. The graft (fig. 4) was left for one and a half months; it contained follicles and ova. The stroma had become degenerate in places.

Four other similar experiments, while not entirely satisfactory, met with some success. In one of these the ovaries were transplanted to a male rat. 'The graft showed recognisable ovarian tissue in parts, but had undergone very considerable degeneration.

A number of experiments were also performed in which ovaries from one rat were grafted under the skin on the anterior abdominal wall of another rat. In three such cases some success was obtained, but a larger number of grafts was absorbed than when the implantation was intraperitoneal.

It will be observed from the foregoing account of our experiments that it is possible to excise and graft ovaries in such a way that in many cases the grafts exhibit the characteristic histological features of ovarian tissue. The germinal epithelium had, however, always become absorbed in our experiments. In other cases a certain amount of degenerative change took place, only certain elements of the tissue being recognisable after the lapse of several months ; thus the stroma might present its normal appearance 
while the follicles had disappeared, or the greater part of the graft might be composed of luteal tissue alone.

It will further be seen that the cases of transplantation classed as successful are fewer in heteroplastic than in homoplastic implantation. Of our two successful heteroplasts, one was a graft into a rat of the same litter, while the other was possibly but not certainly a similar case.

The maintenance of the histological characters in successful grafts points to retention by them of function, and further evidence of their functional integrity is derived from the fact that the constituents of the graft varied according to the period in the reproductive cycle at which the animal was killed. At the commencement of the breeding season large follicles were found in the graft; at a later period corpora lutea were present. It is to be presumed, therefore, that the grafts passed through the same phases of functional activity as normal ovaries.

\section{Condition of Uterus after Ovarian Transplantation.}

We examined the histological condition of the uterus in those cases where the ovaries had been removed and transplanted to another position in the body. The appearance of the uterus was found to bear a relation to the microscopic structure of the graft. If the latter bad retained unaltered, or with little alteration, the typical characters of ovarian tissue, the uterus was found undegenerated ; thus in Experiment 8 of our series of homoplasts (p. 596), in which the ovaries had been transplanted for six months, the uterus was normal. If, however, the graft had failed to "take," the uterus exhibited undoubted evidence of degeneration. Where the graft had been successful, on examining it and the uterus post mortem we found that each organ had the appearance appropriate to the time of year and stage of reproductive cycle at which the animal was killed. Thus in one case where the graft had met with some measure of success, and the animal was killed at the beginning of the breeding season, the ovary contained large follicles and the uterus was in the condition which has been described as the recuperative stage of the ostrous cycle.

In the case of transplantation from rat to rat, uterine degeneration was found, as in homoplastic implantation, to be arrested by a successful graft.

\section{General Conclusions.}

In our previous paper (1905) we supplied evidence in support of the view that heat and menstruation are induced either directly or indirectly through the activity of an internal secretion or hormone arising in the ovaries, while we adduced further evidence that the corpus luteum provides a secretion which assists in the nourishment of the embryo during the first stages of pregnancy. In the present paper we show that the existence of ovarian tissue is an essential factor in normal uterine nutrition ; and further, that the nature of the ovarian influence upon the uterus is chemical rather than nervous, 
since the transplanted ovaries, while still maintaining their functions (at least in many cases), had lost their normal nervous connections. It is extremely probable, therefore, that the uterus is dependent for its proper nutrition upon substances secreted by the ovaries, not merely at the heat periods and during pregnancy, when they show their greatest activity, but throughout the whole of the cestrous cycle.

The expenses of the investigation were defrayed by grants from the Government Grant Committee and from the Carnegie Trust.

\section{POSTSCRIPT.}

Since this paper was communicated, Carmichael has published a paper on "The Possibilities of Ovarian Grafting in the Human Subject." He describes numerous experiments on homoplastic transplantation in rabbits, the majority of which were successful in parts. Carmichaec is of opinion that in larger animals, and in the human subject, the ovary when transplanted is unlikely to retain its complete functional activities owing to partial degeneration, although it is probable that portions of the graft may be got to survive.

\section{REFERENCES TO LITERATURE.}

Amico-Roxus, Areh. di. Obstet. e. Gin., 1901.

Arfind, Naturforscher-Versammlung, 1898, Dusseldorf.

Cramer, Münch. Med. Woch., 1906.

Basso, Arch.f. Gynäh, vol. lxxvii., 1905.

BeL,L, Liverpool Medico-Chirurgical Jour., 1906.

Benkiser, Verhandl. der deutsch Gesell. f. Gynäk., Fourth Congjess, Leipzig, 1891.

Bond, Brit. Med. Jour., Part II., 1906.

Buys and VANDervelte. Quoted by Knauer.

Canmohate, Jour. Obstet. and Gyniec., vol. xi., 1907.

Donan, Jour. Olstet. and Gyn., vol. ii., 1902; Lancet, Part II., 1905.

D) duey, Intem. Gyn. Congress, Amsterdam, 1899.

Foi, Arch. Ital. de Biol., vol. xxxiv., 1900.

GLass, Med. News, New York, 1899.

Grigoriefr, Centralbl. f. Gynäl., vol. xxi., 1899.

Herlitzka, Arch. Ital. de Biol., vol. xxxiv., 1900.

Hobday, Veterinary Record, vols. xii. and xiv.; Vet. Jour., vol. lxii., 1906.

IIofmerer, Zeitsch.f. Crel. u. Gynäh:, vol. v.

Knauer, Arch.f. Gynäh, vol. Ix., 1900.

Iimon, Jour. de Phys. et de Path. Gen., vol. xvi., 1904.

M'Cone, Amer. Jour. of Obstet., vol. xl, 1899.

Malshall and Jolly, Phil. Trans. B., vol. cxcviii., 1905.

Merenilh, Brit. Med. Jour., Part I., 1904.

Morris, New York Med. Jour., 1895 and 1906 ; Amer. Jour. of Obstet., 1903.

Pinard and Pozzi. See Brit. Med. Jour., Part I., 1906 (p. 883). 
Rimbert, Arch.f. Entwick-Mechanik., vol. vii., 1898.

Romanes, Darwin and After Darwin, vol. ii., 1895.

Rubinsteis, st Peters. Mediz. Woch., 1899.

Schultz, Centralbl.f. All. Path. u. Path. Anat., vol. xi., 1900.

Shattock and Seligmann, Royal Soc. Proc., vol. Ixxiii., 1904.

SoкoLoff, Arch.f. Gynäl., vol. li., 1896.

\section{DESCRIPTION OF THE PLATES.}

The figures were drawn by Mr Richard Murn, of the Pathological Department, University of Edinburgh.

\section{Plate T.}

Ficr. 1. Grafted ovary from a case of homoplastic implantation, showing normal Graafian follicles with membrana granulosa, a small follicle with ovum, a degenerate follicle without membrana granulosa, and cysts lined by stratified squamous epithelium. The cysts are not improbably derived from other follicles. The graft was allowed to remain for two and a quarter months, and the rat was killed before the commencement of the normal breeding season. $\times 40$ diam.

Fig. 2. Homoplast showing follicles, an ovum, and corpora lutea. The graft was left for two months, and the rat was killed during the breeding season. $\times 80$ diam.

Fig. 3. Heteroplast showing a highly vascular corpus luteum. Graft left for three and a quarter months. $\times 80$ diam.

\section{Plate II.}

Fig. 4. Heteroplast showing follicles with normal membrana granulosa, interstitial cells, etc. Graft left for one and a half months. $\times 120$ diam.

Hig. 5. Transverse section of normal uterus of rat, showing glands, etc. $\times 40$ diam.

Fig. 6. Transverse section of uterus of rat castrated six months previously. The lumen is small, the mucosal glands inconspicuous, the muscular wall thimed, and the fibrons tissue increased. $\times 40$ diam.

Fig. 7. Transverse section of uterus of rat in which homoplastic implantation had been performed two months previously. The uterus is practically normal. $\times 40$ diam. 


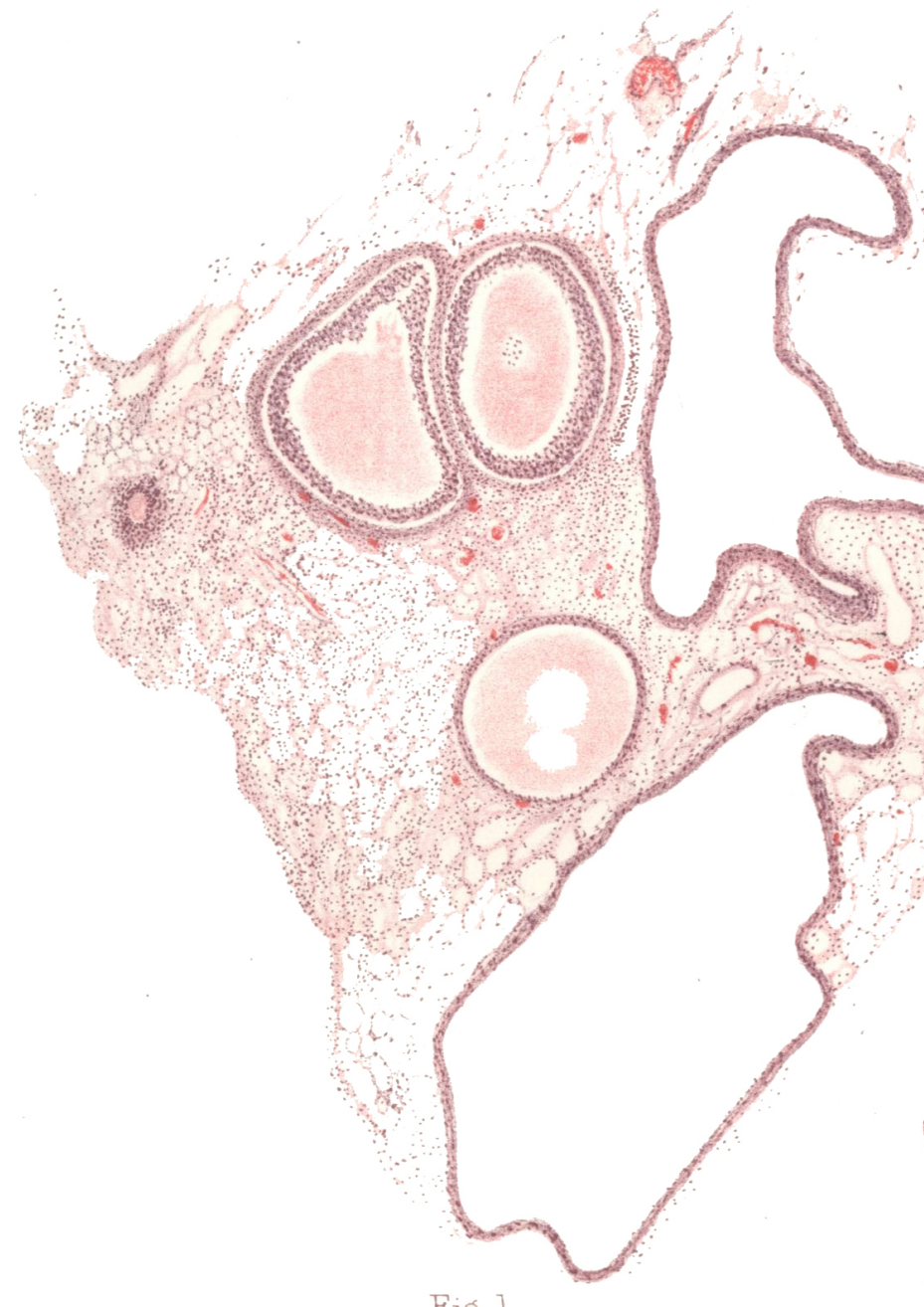

Fig. 1
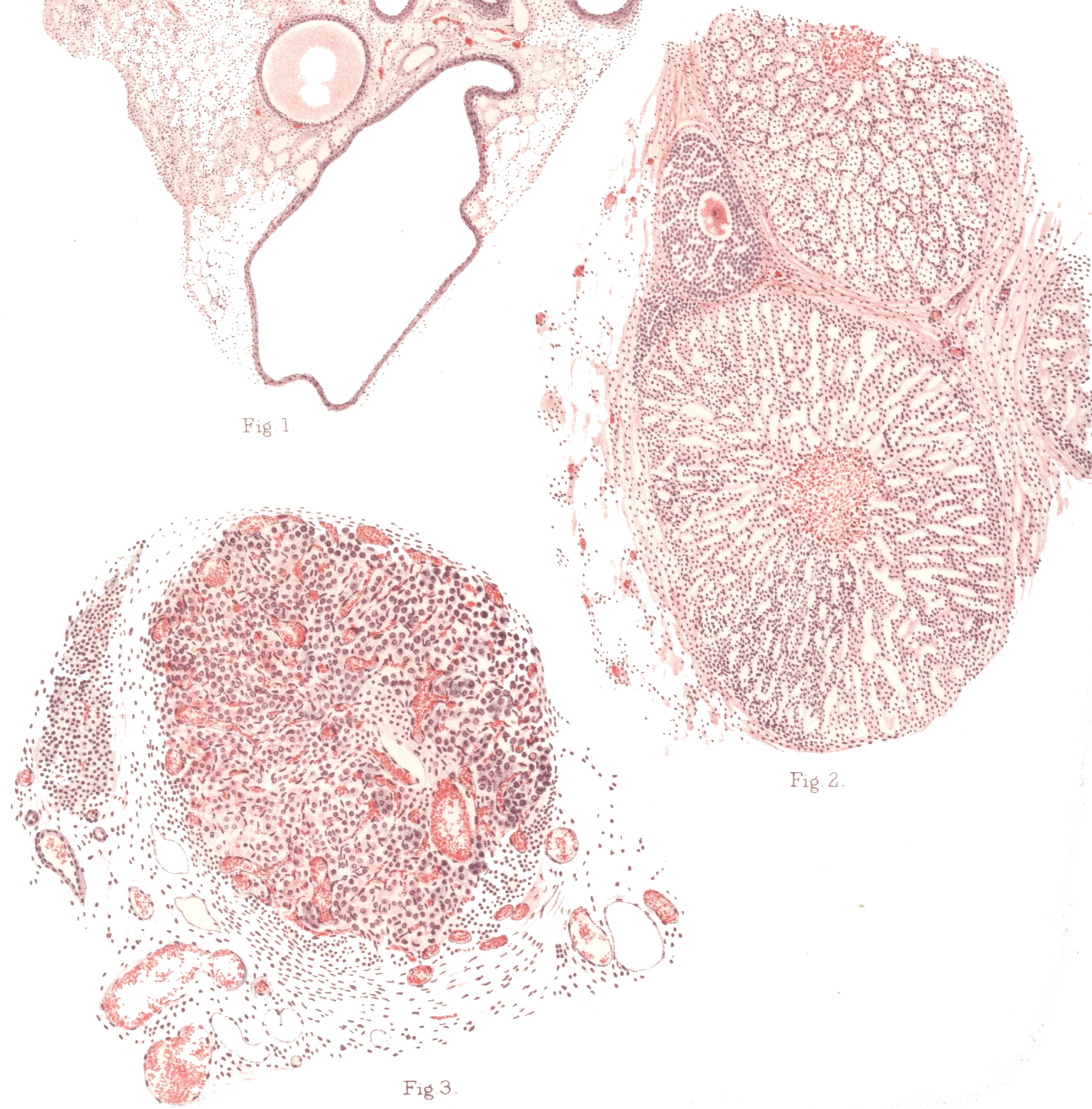
A C 

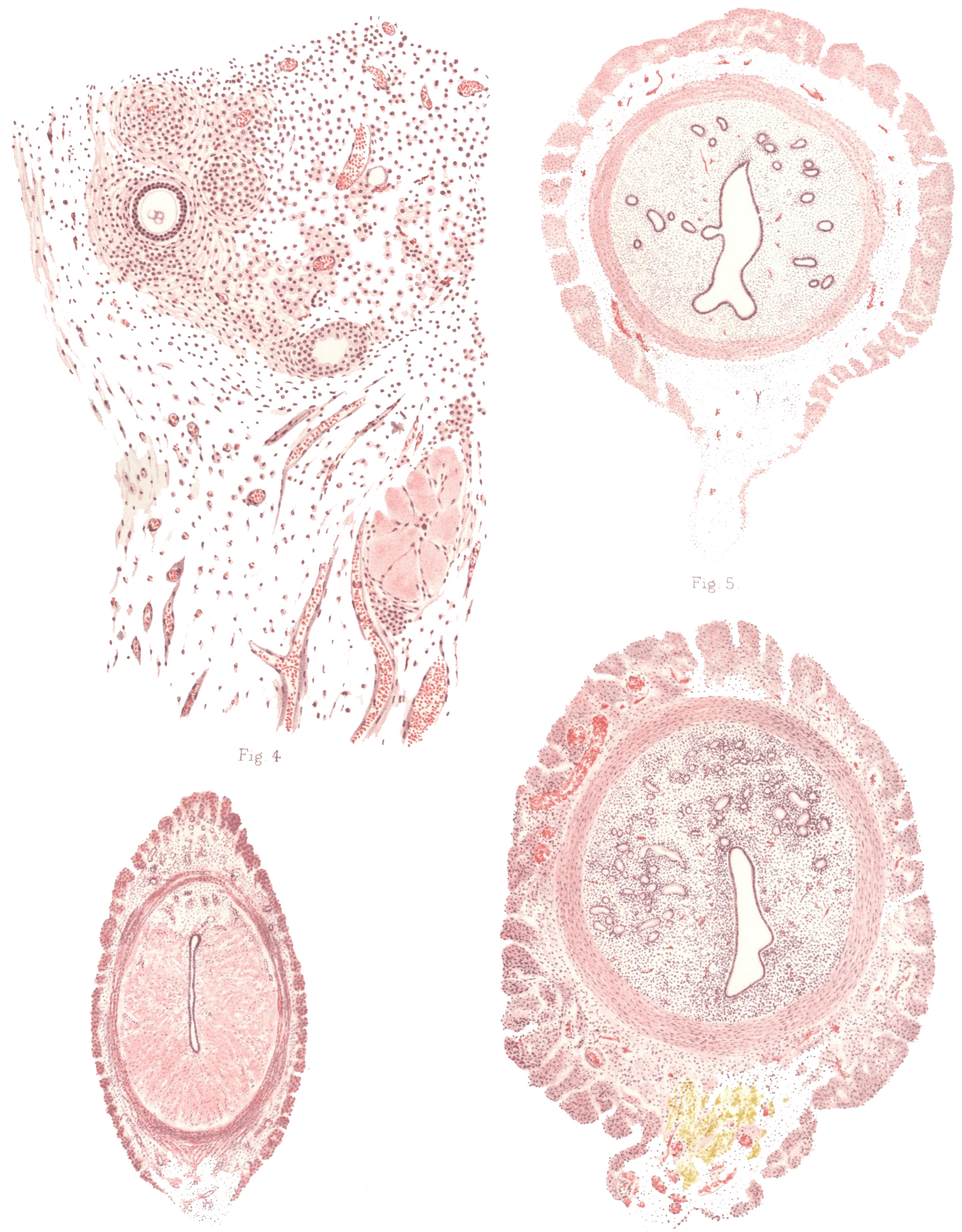

Fig. 6 